\title{
Developing an Augmented Reality Application in the Framework of Architecture Degree
}

\author{
Albert Sanchez Riera \\ Dept. of Architectural Graphic \\ Expression II. \\ UPC (Barcelona Tech) \\ School of Building Construction of \\ Barcelona. EPSEB \\ C/. Gregorio Marañón, 44-50, 08028. \\ Barcelona, Spain \\ +34934016290 \\ albert.sanchez.riera@upc.edu
}

\author{
Ernest Redondo Dominguez \\ Dept. of Architectural Graphic \\ Expression I. \\ UPC (Barcelona Tech) \\ School of Architecture of Barcelona. \\ ETSAB \\ Avda. Diagonal, 649, 2. 08028 \\ Barcelona, Spain \\ +34934016384 \\ ernesto.redondo@upc.edu
}

\author{
David Fonseca Escudero \\ Dept. of Architecture \\ La Salle Barcelona \\ Quatre Camins 2, 08022 \\ Barcelona, Spain \\ +34 932902430 \\ Universitat Ramon Llull, Spain \\ fonsi@salle.url.edu
}

\begin{abstract}
We describe the development, implementation and evaluation of an augmented reality (AR) application for mobile devices. It has been particularly intended to be used in educational environments. This application has been called U-AR, and is based on optical image recognition from real environment images, to act as markers. Once they are associated with virtual information (3D architectural models, in our case), the application allows viewing, scaling, and positioning it interactively and in real time. Some improvements have been implemented compared to existing commercial ones, such as the ability to view different models consecutively with a single marker and the possibility to move these computer-generated objects around the scene.

The main objective was to assess the feasibility of using AR on mobile devices in educational environments. In addition we evaluated academic performance improvement using this technology. Validation was done through a case of study. It was carried out by Architecture students of the ETSAB, (UPCBarcelona-Tech) outdoor. Results obtained by student's architectural proposals, after using this technology, and by questionnaires responses, demonstrated the application suitability as a new tool to be used in learning processes.
\end{abstract}

\section{Categories and Subject Descriptors}

H.5.1. [Multimedia Information Systems]: Artificial, augmented, and virtual realities; Evaluation/methodology. K.3.1. [Computer Uses in Education]: Collaborative learning, Distance learning.

\section{General Terms}

Design, Experimentation, Human Factors.

\section{Keywords}

Augmented reality, mobile devices, learning processes.

Permission to make digital or hard copies of all or part of this work for personal or classroom use is granted without fee provided that copies are not made or distributed for profit or commercial advantage and that copies bear this notice and the full citation on the first page. To copy otherwise, or republish, to post on servers or to redistribute to lists, requires prior specific permission and/or a fee.

UXeLATE'12, November 2, 2012, Nara, Japan.

Copyright 2012 ACM 978-1-4503-1593-7/12/11...\$15.00.

\section{INTRODUCTION}

Specific application development for educational purposes, using augmented reality technology (AR), is an educational research project that arises from the Interest Group for Logistics and Education in Architecture, GILDA. It is an interuniversity group centered in the architectural field, assigned to the Project RIMA, (Research and Innovation in learning methodologies) from ICE, (Institute of Education Sciences at the Polytechnic University of Catalonia, UPC), which is specialized in the field of education technological disciplines.

This project aims to respond to the growing need of new technologies incorporation in learning processes. They are alternative to traditional ones, and provide new tools to improve motivation and student academic performance, enabling a greater acquisition of skills by the student and, as we'll see, reverting in better academic performance. To evaluate its feasibility, a case study was assessed. It was conducted on a Computer Applications (APF) course at the UPC.

Which aims to complete student's training and technical resources to design, analyze, develop and present architectural projects under the overall theme of the course of Housing and Urban environment. This is embodied in two main directions: the utilization of digital image processing and the use of agile tools to create 3D virtual scenes. Results demonstrated that better results are achieved when students use AR technologies on mobile devices (running on Android and iOs software).

\section{THEORETICAL, PEDAGOGICAL AND DIDACTIC FOUNDATIONS}

Learning, by definition, is the process by which memories are built, while memory is the result of learning [1]. In recent years, the desire of learning process improvement has led a transition to a technologically enhanced classroom, where computers, media players, interactive whiteboards, internet, web 2.0 tools, and games have been incorporated. The emergence of the World Wide Web revolutionized how to access, share and encode information, playing a key role in learning. E-mail and mobile phones have transformed the way we communicate, and the list of technologies that can be useful in learning processes is huge and constantly growing, not being simple to define which may be suitable for learning and which are not [2].

More recently, immersive technologies in virtual and augmented reality worlds have been used. Its usefulness has been assessed by 
numerous international projects [3], [4], [5], [6], [7], [8], [9], [10]. These experiences, that use augmented reality in the area of entertainment and education, demonstrated the great potential of this technology. But in education, it may still be considered as a new tool, and further investigation is necessary, paying special attention to user experience and learning processes [11], because, despite the ongoing effort to technology implementation, there is also the need to immerse students in new learning environments, these in turn, continuously changing [12].

Teachers faces the challenge of constantly be updated to provide new forms of teaching, focusing on the acquisition of generic skills in which students must construct their own knowledge through constructivism, proposed by Piaget [13] and meaningful learning proposed by Ausubel [14]. Thus, students must relate new information with that one that already owns, as opposed to memorize contents through classical exposure and repetition. From this constructivist approach, learning can be facilitated, but each person reconstructs his own inner experience. In this way we could consider that knowledge is unique to each person, and depends of their own internal reconstruction and subjective reality. The role of teachers is reduced, in many cases, to provide information to students, being a guide and facilitator of knowledge acquisition.

In spite of this, we can frequently find situations in the classroom where educational contents are simply exposed and presented without any interaction by the student, that receive passively new concepts to be memorized, getting bored easily and consequently minimizing their learning. Student motivation is essential to reverse this situation [10].

When students are active and motivated they engage, participate, and interact with content, cognitive mechanisms of learning are activated, maximizing the learning. The next question that the teacher should ask is: Can the technologies of learning (TEL, Technology Enhanced Learning) change this attitude? For Dror [2], this change depends on whether technology is used as a means to promote what he calls the three learning C's: Control, Challenge and Commitment.

There is where AR technology, through motivation and students engage, can helps to improve the learning process performance [10], [15]. Augmented reality and virtual reality (VR) share some common features such as immersion, navigation and interaction [16]. However, AR has two main advantages over VR: Allow collaborative experience in a real scene. So users can work with computer-generated objects as if they were real objects in a real environment, in real time; and Tangible Interaction. By superimposing virtual objects in a real environment through markers, user can modify and manipulate the scale, position and location of virtual objects. This interaction "tangible", achieved simply by modifying these markers, becomes an extremely simple and natural interface that requires no prior learning by the user. So we could say that RA technology, by providing new interaction possibilities, promote student active participation in its own knowledge construction. Thus, it becomes a suitable medium to be used in schools [17].

By designing an AR mobile tool we will give students control ownership of their learning process. Besides that, experience will be a challenge when student confronted with it, in a new way. Then learning will be more effective. Finally, we can say that the AR implementation effort will not help, if student don't make a commitment effort to complete the exercise. As we see commitment is the foundation of learning, however, student's engagement is not easy..

\section{U-AR application design.}

The application ought to allow the creation of AR content channels and its visualization via a mobile device. Each channel consists on 3D models series that students have previously generated and associated to pre-defined markers (limited to five). As we said before, these markers are images from real world that the application detects to overlay associated virtual information.

One of the advantages that differentiate U-AR other commercial applications (ArMedia, Aurasma, junaio, layar...) is the fact that a single marker contains several models, which is useful in architectural learning, to facilitate comparison of different models, options, or proposals, without varying the reference image. It also allows the positioning of each object relative to the marker independently, which is essential to minimize AR optical marker based recognition systems, that originated so many problems of stability in the scene [18]. Outdoors, these limitations are: strong dependence of ambient light conditions, camera distance and marker size relationship, and the fact that the physical environment is altered by fiducially markers. Using U-AR, user may be near a marker, which is readily recognizable, and once the $3 \mathrm{D}$ model is overlaid, it can be moved to the desired position, maintaining the relationship of size and perspective relative to marker position (which must be always visible).

For its implementation QCAR Augmented Reality library was used. It is an augmented reality SDK (software development kit) with proprietary license developed by Qualcomm Austria Research Center for Android and IOS platforms. The main difference with traditional Artoolkit libraries is the use of real images from environment, instead of typical squared markers.

The process has been divided into two parts. On the one hand, there's a virtual-contents manager program that runs on student's desktop computers, and lets them to create and manage content channels. User can associate one or several models to one marker choosing initial visualization scale, and channel and $3 \mathrm{~d}$ models name (fig.1). The programming language we decided to use is Java. One of the biggest advantages of Java is that it runs on a virtual machine, so that a Java application is independent of the operating system in which is executed. So it could be used on any computer, whether Mac, Windows or Linux.

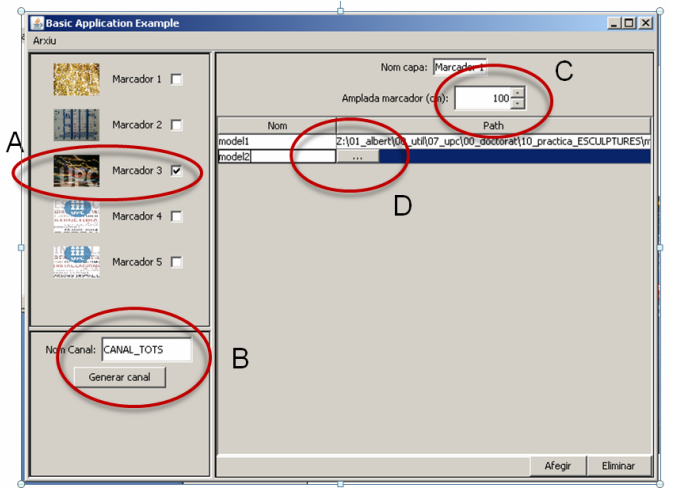

Fig. 1.- Virtual-content manager interface. A: images used as markers; B: cannel name; $C$ : initial scale; D: virtual models selection 
On the other hand we have the mobile device application, which recognize markers using the device camera, register them, and shows virtual information overlapped to the real scene. Application allows student to alternate easily its own generated content, and also to move and to scale in an intuitive and tactile interface.

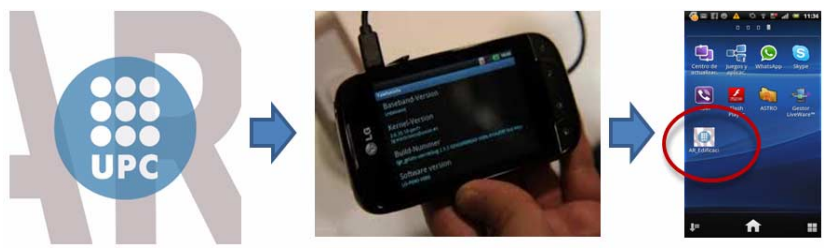

Fig. 2.- Logo, installation and application on mobile device.

When students finished this process, a folder is generated. It contains an *.xml (Extensible Markup Language) file that has all channel generated structure, $3 \mathrm{dmodels}\left({ }^{*}\right.$.obj and *.mtl) and texture files, organized in subfolders. This information is needed to be loaded on application in order to read channel information.
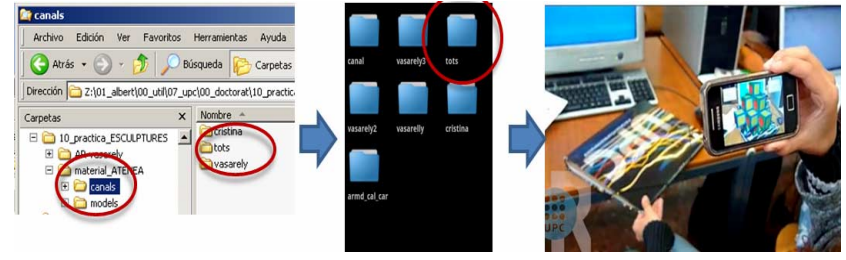

Fig. 3.- Sample Loading and Displaying generated channel.

$\mathrm{Xml}$ file is widely used to describe data structures and allows communication between different applications. In our case, the content manager creates an XML file and mobile application interprets the document to load and display correctly virtual model (Fig.4).

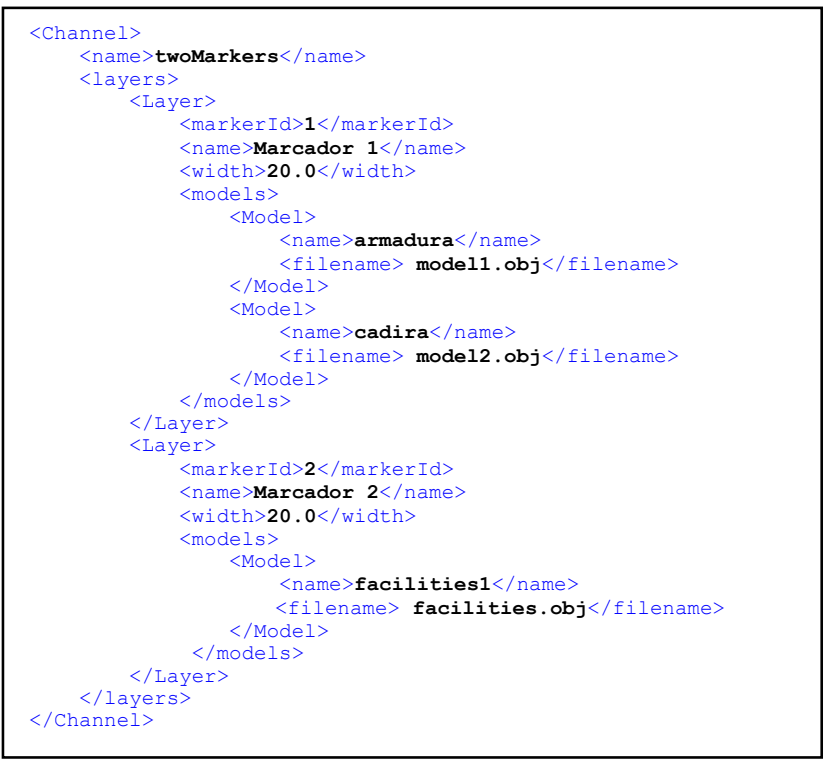

Fig.4.- XML document structure sample.

For rendering we use OpenGL (Open Graphics Library), as a standard specification defining a cross-language, multi-platform API (Application Programming Interface) widely used for writing applications and simulating physics.

Finally, in order to get a better integration of virtual models in the scene we were focused on occluders recognition and lighting simulation. Because most of the times, the virtual model lacks realism and are not integrated sufficiently into the scene to be credible. This problem takes on special significance to visualize architectural proposals, because a non-integrated scene may seem unlikely and unattractive (Fig. 5).

To solve the problem of lighting conditions differences between real environment and virtual objects superimposed, student's generated models had to be single meshes, and they incorporated textured maps simulating lighting conditions from real environment. For occluders implementation we followed the concept of phantoms suggested by [19]. The main idea is to generate a model identical to real-world one, that produces an effect of occlusion on the virtual object.
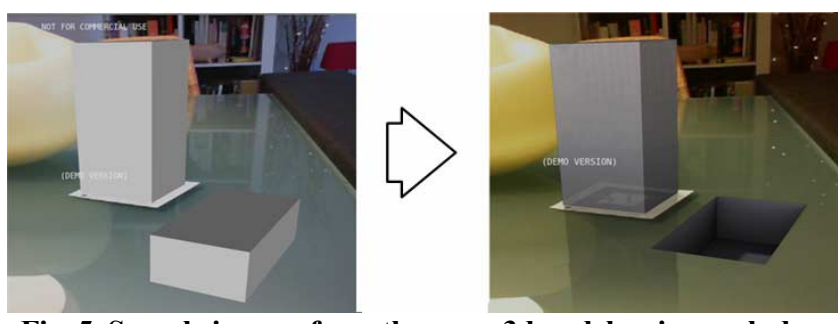

Fig. 5. Sample images from the same 3dmodel, using occluders and lighting integration modeling techniques.

\section{Case Study}

In this case, we focused on the study of interventions in the urban landscape of Barcelona with ICT help. Following these premises, we worked on the Plaza Flassaders (Fig. 6), who recently completed the construction of the extension of the Picasso Museum in 2009 .

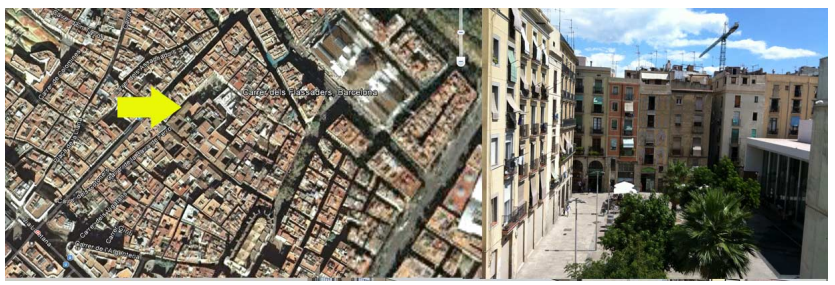

Fig. 6. Case study location.

The working group is composed of 25 students divided into three groups: a control group, consisting of 8 users who do not have smartphones or AR technology is not supported (No_AR). They will follow the traditional course based on slides; and two experimental groups, which we call iOs (9 students) and Android (8 students) both will be involved in AR specific training. Android users will use the U-AR application and iphone users will use Armedia.

\subsection{Research questions}

In order to investigate the impact of two technologies implementation scenarios: S1 (based on slides) and S2 (based on augmented reality technology on mobile devices), on student academic performance. The research questions were:

1. Are there any differences in academic results depending on which of the two teaching scenarios proposed are used?

2. Is there any difference in student's degree of satisfaction and motivation depending on which of the two teaching scenarios proposed they used? 
The study also included a quantitative analysis to determine usability of U-AR application. Some experiences have been done to evaluate Virtual Environments (VE) usability.

Stanney [20], used a multi-criteria assessment technique to design and evaluate Virtual environments. In our case we were based on ISO 9241-11 which provides usability guidelines [21];

- $\quad$ Effectiveness, defined as the user's ability to complete tasks during the course, in relation to the "accuracy and integrity" that it had been made.

- Efficiency, on the assigned resources, they asked questions related to the expenditure of time and effort for solving the proposed exercise.

- Satisfaction, understood as subjective reactions of users about the course.

\subsection{Procedure}

The whole course was performed in three phases. Augmented reality experience was conducted on the second one.

\subsubsection{First Phase:}

In summary, this phase involved the use of all digital architectural tools knowledge acquired by students throughout their training in previous courses to model existing environment, to select an artistic reference, and to generate a virtual scene incorporating their proposals. Students captured site information through digital photography and vectorial cartography.

Specialized applications as Photomotch, Ptlens, Sketchup were used to rectify images, in order to get basic dimensions and measurements from the environment. They chose an artistic reference, and modeled their proposals using AutoCAD, Rhino, or SketchUp. Student's models were incorporated to the virtual generated scene. They were required to define scale and location, and to render preliminary proposals.

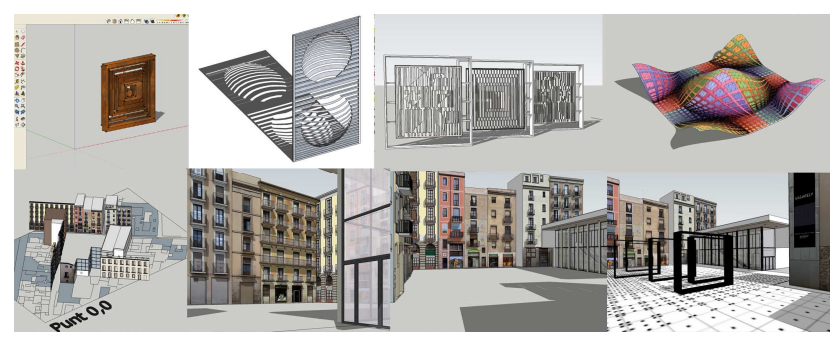

Fig 7. Preliminary student's proposals.

\subsubsection{Second Phase:}

We called this: Visual analysis and adjustments "in site", of their sculpture and urban design proposals using both traditional processes and AR.

In this phase we defined experimental and control groups between the different students of the course. Students were asked about their availability to participate in the experiment. 8 students continue the ordinary course (NO_AR) and the other 17 are divided into two experimental groups. Android (8) and IOS group (9).

Once they visited the site, control group continued developing their proposals in traditional way. They used for that 3dsmax Sketchup, and other 3 dmodeling tools. They made metric analysis of the scale, position and orientation of sculptural models proposed in order to adjust their proposals.
AR groups used U-AR, they generated their own content channels and were able to see their proposals "in site", overlapped to the real environment. They also were able to see different models with the same marker and to verify scale, size, and position comparing different proposals ${ }^{1}$.

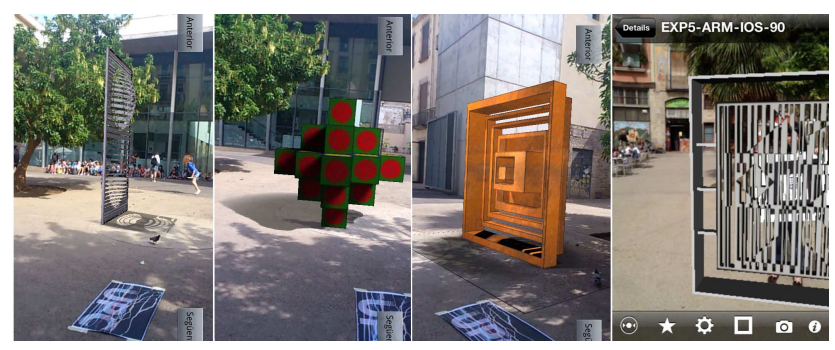

Fig 8. Sample images using U-AR application "in site".

\subsubsection{Third phase: Final Project Presentation}

In this last phase, both groups were required to reconsider their proposals. Reformulation of their project was done. Scale and dimensions of the sculpture, points of view and areas of impact were changed according with "in site" information obtained using traditional an AR scenarios.

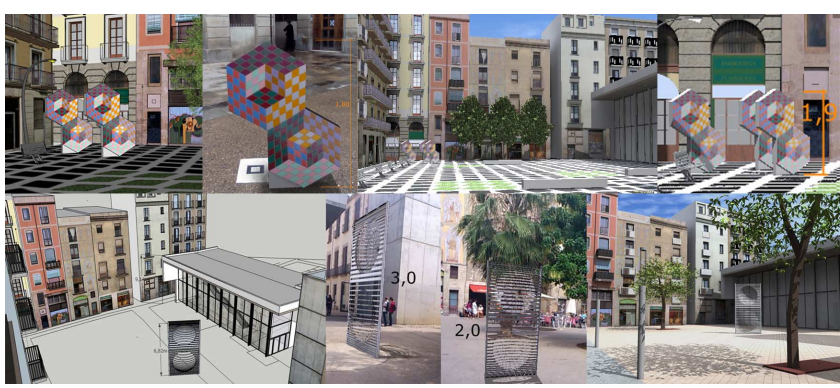

Fig 9. Final presentation results, once student's proposals were reformulated.

\section{EVALUATION}

To evaluate this exercise all students made an architectural proposal in a conventional manner, as we said in point 4.2.1 (first phase). In this case, as mentioned, they designed a sculpture, furniture, or some kind of intervention for a real space choosing an artistic reference. After visiting the site, control group and experimental groups (using AR) reformulate their proposals. Pre and post proposals were evaluated using the following criteria:

- 30\%: Quality of the model presented (textures, light immersion, no. Of polygons, and no. Of textures used).

- $40 \%$ : Integration into the site (scale, position, viability of the proposal...)

- $30 \%$ : Subjective opinion about proposal quality (through other users rating).

Means (from 1to 10) and Std. Deviation of the three groups in the first phase, previous AR training ("PRE"), were very similar:

\footnotetext{
1 A video can be found at: http://youtu.be/2sJnSv_sgPs
} 
Table 1. Previous results of AR training

\begin{tabular}{|c|r|r|r|}
\hline grup_2 & N & \multicolumn{1}{c|}{ Mean } & Std. Deviation \\
\hline Android & 8 & 6.1200 & 1.7154 \\
\hline No_AR & 8 & 6.1662 & 2.2129 \\
\hline ios & 9 & 6.2978 & 2.0043 \\
\hline Total & 25 & 6.1988 & 1.9057 \\
\hline
\end{tabular}

To verify that they are equal groups, we used analysis of variance (ANOVA). The null hypothesis (h0) is that the scores match from different groups (no differences).

The analysis of qualifications "PRE" between the three groups (experimental groups ios and Android, and No_AR, control group), shows that there's not significant differences between groups regarding their qualifications before to conduct training (F2, $22=$ $0.018, \mathrm{p}=0.982$ ).

Table 2. Anova analysis Between groups.

\begin{tabular}{|l|r|r|r|c|l|}
\hline & Sum of Squares & df & Mean Square & F & Sig. \\
\hline Between Groups & 0.146 & 2 & 0.073 & 0.01 & 0.982 \\
\hline Within Groups & 87.014 & 22 & 3.955 & & \\
\hline Total & 87.160 & 24 & & & \\
\hline
\end{tabular}

Upon completion of the proposed course (third phase) students delivered their proposals to be scored as described above. Results showed that experimental groups, which participated in the RA experience, increased their scores.

Table 3. Result of qualifications and gain obtained per group, with PRE and POST presentations:

\begin{tabular}{|l|l|r|r|r|}
\hline & \multicolumn{1}{|c|}{ grup } & nota_pre & nota_post & \multicolumn{1}{c|}{ Gain } \\
\hline \multirow{3}{*}{ Android } & Mean & 6.1200 & 7.5112 & 1.3912 \\
\cline { 2 - 5 } & Std. Deviation & 1.7154 & 0.9918 & 1.4559 \\
& Mean & 6.1662 & 6.0762 & -0.0900 \\
\cline { 2 - 5 } & Std. Deviation & 2.2128 & 2.0716 & 3.6307 \\
\hline \multirow{3}{*}{ ios } & Mean & 6.2977 & 7.8611 & 1.5633 \\
\cline { 2 - 5 } & Std. Deviation & 2.0043 & 1.0982 & 2.0080 \\
\hline \multirow{2}{*}{ Total } & Mean & 6.1988 & 7.1780 & 0.9792 \\
\cline { 2 - 5 } & Std. Deviation & 1.9056 & 1.5992 & 2.5245 \\
\hline
\end{tabular}

To verify that the observed increase, is statistically significant, it is considered as null hypothesis (Ho), the fact that the mean scores do not vary at the end of the proposed training, that is, after the AR training the experimental groups (ios and Android) and the control group did not increase their results differently.

The obtained values indicate that experimental groups (ios and Android) have significant differences between mean values $($ sig $<0,05)$ before and after the course, thus the null hypothesis (Ho) is rejected, and we can affirm that these groups had improved results.
Table 4. Results comparing values obtained in pre-and post-test with the Student $t$ test for paired series.

\begin{tabular}{|c|c|c|c|c|c|c|c|}
\hline \multirow[b]{4}{*}{ Pair 1} & \multirow[b]{4}{*}{ PRE--POST_NOAR } & \multicolumn{6}{|c|}{ Paired Differences } \\
\hline & & \multirow{2}{*}{ Mean } & \multicolumn{2}{|c|}{$95 \%$ Conf. Int. dif } & \multirow{2}{*}{$\mathbf{t}$} & \multirow{2}{*}{ df } & \multirow{2}{*}{$\begin{array}{l}\text { Sig. } \\
\text { (2- }\end{array}$} \\
\hline & & & Lower & Upper & & & \\
\hline & & 0.09 & -2.94 & 3.12 & 0.07 & 7 & 0.946 \\
\hline Pair 2 & PRE-POST_ios & -1.56 & -3.11 & -0.19 & -2.34 & 8 & 0.048 \\
\hline Pair 3 & PRE-POST_And & -1.39 & -2.60 & -0.17 & -2.70 & 7 & 0.031 \\
\hline
\end{tabular}

However, in the control group, which carried out the activity through conventional training, table shows no significant differences between the mean values i PRE POST, therefore no improvement in the scores is achieved. It is accepted in this case the null hypothesis null (Ho).

\subsection{U-AR application usability}

As we mentioned before, we evaluated user's assessment using questionnaires based on ISO 9241-11, which provides usability guidelines (effectiveness, efficiency and satisfaction). Responses average were very similar, ranged from 3.59 to 3.73 , out of 5 .

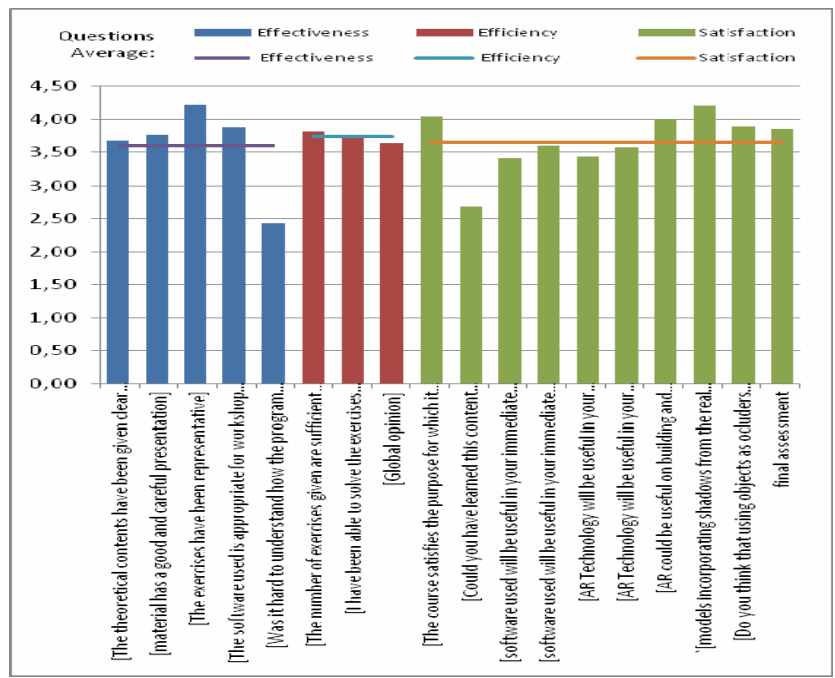

Fig. 10. Final average rating

The overall assessment of the courses was rated 4.18 points out of 5 . This gives an idea of the degree of satisfaction achieved.

In a correlation analysis between the course global opinion and the other variables, a high correlation (0.68) was detected with: the representativeness of the exercise. So this variable seems crucial to the success of this kind of teaching experience. Global opinion was not so correlated with the fact of being able to solve the exercises independently. The strongest correlation (0.89), however, was with obtained gain variable. Students with little gain between pre and post qualifications rated worse than student from experimental groups (with higher gains). On other hand, variables related to prior knowledge of technology and to the use of different software and operating systems did not correlate significantly with the course global opinion.

\section{Conclusions}

In relation to U-AR, and the use of new technology on learning processes with mobile devices, some advantages have been found over other commercial applications such as: the possibility to 
display several 3Dmodels without changing the marker (which allows to compare different architectural proposals and hypotheses); and the ability to move objects in the scene. These benefits were crucial to the viability of the study outdoors, helping to minimize the problem of stability in the scene of that kind of AR systems, based on optical recognition.

Related to research questions, we found significant differences in academic results depending on which of the two teaching scenarios were used. (Research question 1). And results show significant differences in student's satisfaction and motivation depending on which of the two teaching scenarios were proposed (research question 2). However, similar experiences with larger groups must be repeated to compare these results.

Results suggest that combination of an attractive technology and the user-machine interaction that involves the AR, make students feel more motivated. They created dynamic photomontage and architectural proposals, for visual evaluation in a real environment, getting involved on their own knowledge construction, and consequently, development and evolution of graphic competences and space skills were increased in a shorter learning periods, and their academic performance was significantly improved.

\section{REFERENCES}

[1] L. R. Squire, Memory and Brain. Oxford University Press, 1987.

[2] I. E. Dror, "Technology enhanced learning: The good, the bad, and the ugly," Pragmatics \& Cognition, vol. 16, no. 2, pp. 215-223, Jan. 2008.

[3] T. L. Andersen, S. Kristensen, B. W. Nielsen, and K. Grønbæk, "Designing Augmented Reality Board Games : The BattleBoard 3D experience," in Proceeding of the 2004 conference on Interaction design and children: building a community, 2004, pp. 137-138.

[4] R. Galantay, J. Torpus, and M. Engeli, “'living-room'. Interactive, Space-Oriented Augmented Reality," Proceedings of 12th annual ACM conference on Multimedia - MULTIMEDIA'04, 2004, pp. 64-71.

[5] B. Brederode, P. Markopoulos, M. Gielen, A. Vermeeren, and H. de Ridder, "pOwerball: The design of a novel mixed-reality game for children with mixed abilities," Proceedings 2005 conference on Interaction design and children-IDC'05, 2005, pp. 32-39.

[6] Z. Pan, A. D. Cheok, H. Yang, J. Zhu, and J. Shi, "Virtual reality and mixed reality for virtual learning environments," Computers \& Graphics, vol. 30, no. 1, pp. 20-28, Feb. 2006.

[7] R. Budhiraja, S. Verma, and A. Pandey, "Designing interactive presentation systems for classrooms," Proceedings of 28th ACM International Conference on Design of Communication - SIGDOC'10, 2010, p. 259.

[8] C. Alvarez, R. Alarcon, and M. Nussbaum, "Implementing collaborative learning activities in the classroom supported by one-to-one mobile computing: A design-based process," Journal of Systems and Software, vol. 84, no. 11, pp. 1961-1976, Nov. 2011.
[9] C.-M. Chen and Y.-N. Tsai, "Interactive augmented reality system for enhancing library instruction in elementary schools," Computers \& Education, vol. 59, no. 2, pp. 638652, Sep. 2012.

[10] Á. Di Serio, M. B. Ibáñez, and C. D. Kloos, "Impact of an Augmented Reality System on Students' Motivation for a Visual Art Course," Computers \& Education, pp. 1-11, 2012.

[11] C. Portalés Ricart, "Live LEGO House: a Mixed Reality Game for the Edutainment 19 - 28.," Schottish Online Journal of E-Learning, vol. 1, no. 1, pp. 19-28, 2007.

[12] T. N. Arvanitis, A. Petrou, J. F. Knight, S. Savas, S. Sotiriou, M. Gargalakos, and E. Gialouri, "Human factors and qualitative pedagogical evaluation of a mobile augmented reality system for science education used by learners with physical disabilities," Personal and Ubiquitous Computing, 13(3), pp. 243-250, 2007.

[13] J. Piaget, H. E. Gruber, and J. J. Vonèche, The essential Piaget. J. Aronson, 1995.

[14] D. P. Ausubel, Educational psychology: a cognitive view. Holt, Rinehart and Winston, 1968.

[15] R. CHEN and X. WANG, "An Empirical Study on Tangible Augmented Reality Learning Space for Design Skill Transfer," Tsinghua Science \& Technology, vol. 13, no. October, pp. 13-18, Oct. 2008.

[16] M. Dunleavy, C. Dede, and R. Mitchell, “Affordances and Limitations of Immersive Participatory Augmented Reality Simulations for Teaching and Learning," Journal of Science Education and Technology, vol. 18, no. 1, pp. 722, Sep. 2008.

[17] C. Portalés Ricart, "Entornos multimedia de realidad aumentada en el campo del arte," Universidad politecnica de Valencia, 2008.

[18] E. Redondo, A. Sánchez Riera, and J. Puig, “Gironella tower in Gerunda, teaching roman architecture, using 3D modeling and augmented reality. A case study," in S.A.V.E. Heritage - International Forum S.A.V.E. Heritage Safeguard of Architectural, Visual, Environmental Heritage, Capri, 2011, pp.102-1-102-9.

[19] A. Fuhrmann, G. Hesina, F. Faure, and M. Gervautz, "Occlusion in collaborative augmented environments," Computers \& Graphics, vol. 23, no. 6, pp. 809-819, Dec. 1999.

[20] K. M. Stanney, M. Mollaghasemi, L. Reeves, R. Breaux, and D. a. Graeber, "Usability engineering of virtual environments (VEs): identifying multiple criteria that drive effective VE system design," International Journal of Human-Computer Studies, 58(4), pp. 447-481, 2003.

[21] J. Martin Gutierrez, "Estudio y evaluación de contenidos didácticos en el desarrollo de las habilidades espaciales en el ámbito de la ingeniería. Doctoral Thesis," Universidad politecnica de Valencia, 2010. 